\title{
The association between norepinephrine and metabolism in patients with major depression
}

\author{
Jesper Futtrup ${ }^{\mathrm{a}, *}$, Merete Nordentoft ${ }^{\mathrm{b}}$, Betina Elfving ${ }^{\mathrm{c}}$, Jesper Krogh ${ }^{\mathrm{b}, \mathrm{d}}$

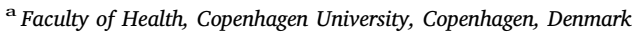 \\ ${ }^{\mathrm{b}}$ Mental Health Centre Copenhagen, Copenhagen, Denmark \\ ${ }^{\mathrm{c}}$ Translational Neuropsychiatry Unit, Aarhus University, Aarhus, Denmark \\ d Department of Endocrinology, Rigshospitalet, University of Copenhagen, Denmark
}

\section{A R T I C L E I N F O}

\section{Keywords:}

Depression

Cardiovascular risk

Norepinephrine

Metabolism

\begin{abstract}
A B S T R A C T
Background: Previous studies indicate that levels of plasma norepinephrine (p-NE) are altered in depressed patients. However, it is unclear whether altered NE metabolism is involved in the pathogenic association between depression and cardiovascular disease. The aim of the present study was, firstly, to investigate if p-NE levels differ between patients with major depression and healthy controls. Secondly, the study sought to assess the associations between p-NE and metabolic variables in all participants. The third and final aim of the study was to assess if the associations between p-NE and metabolic variables are influenced by disease status (depression vs. healthy).

Methods: 108 patients with major depression and 44 healthy controls were tested for levels of p-NE and metabolic variables that affect cardiovascular risk.

Results: The median level of p-NE in depressed patients (DSM-IV) was $2636 \mathrm{pg} / \mathrm{ml}$, (IQR 2094-3143) and $2279 \mathrm{pg} / \mathrm{ml}$ (IQR 2007-2562) in non-depressed controls $(\mathrm{p}=0.013)$. However, the difference between $\mathrm{p}-\mathrm{NE}$ levels was non-significant when adjusted for daily smoking $(p=0.138)$. Significant associations $(p \leq 0.05)$ were observed between p-NE and p-lipids, mean arterial blood pressure, p-insulin, quantitative insulin sensitivity check index as well as inflammatory markers.

Conclusions: Elevated levels of p-NE observed in patients with major depression were attributable to daily smoking, rather than to the depressive disorder. Important associations were found between p-NE and metabolic variables that affect cardiovascular risk. This is interesting from a clinical point of view, since affected individuals may benefit from simple and inexpensive treatments that influence sympathetic activity. All associations were independent of disease status.
\end{abstract}

\section{Introduction}

Depression is a common, serious, and often reoccurring mood disorder considered to be a leading cause of disability adjusted life years (Ferrari et al., 2013). According to the World Health Organization, by 2030 unipolar depression is expected to be the second highest contributing factor to the global burden of disease, making depressive disorders a major global public health concern (Mathers \& Loncar, 2006).

Clinical evidence shows a strong bidirectional comorbidity between depression and cardiovascular disease (CVD) (Cuijpers \& Smit, 2002; Halaris, 2009; Hare, Toukhsati, Johansson, \& Jaarsma, 2014; Kuehl, Penninx, \& Otte, 2012). Multiple pathogenic mechanisms appear to contribute to the increased cardiovascular risk in depressed patients, e.g. the effects of depression on lifestyle behaviour (Whooley et al., 2008), on the immune system (Zahn et al., 2013), on platelet activity (Musselman et al., 1996), on endothelial function (Sherwood, Hinderliter, Watkins, Waugh, \& Blumenthal, 2005), on the autonomic nervous system (Carney et al., 2001) and on hypothalamic-pituitaryadrenal (HPA) activity (Pariante \& Lightman, 2008). Nowhere in the literature, however, have the effects of these factors been proven sufficient to account for the twofold risk of both CVD incidence and progression that depression appears to confer (Davidson, 2013). Possibly, the pathogenic mechanisms may further increase the risk of CVD when combined, but whether another specific variable is accountable or can be used as a predictor of CVD risk in depressed patients remains unclear (DiVincenzo, Reber, Perera, \& Chilian, 2014).

Interestingly, chronic stress has proven to influence and strongly

\footnotetext{
* Corresponding author.

E-mail address: plg252@alumni.ku.dk (J. Futtrup).
} 
precipitate cardiovascular dysregulation and depressive illness (DiVincenzo et al., 2014; Steptoe \& Kivimaki, 2012). Stress triggers release of corticotrophin-releasing hormone which plays a role in the pathophysiology of depression by activating the HPA-axis and exciting norepinephrinergic neuronal cell bodies of the locus coeruleus (Bissette, Klimek, Pan, Stockmeier, \& Ordway, 2003; Heuser et al., 1998). The latter results in increased activity of the sympatho-adrenal-medullary axis and overall peripheral sympathetic nervous system (SNS) activity (Goldstein, McCarty, Polinsky, \& Kopin, 1983; Thornton \& Andersen, 2006). Therefore, levels of plasma norepinephrine (p-NE), which represent a useful measure to assess sympathetic neural function, may be altered in patients with depression (Grassi \& Esler, 1999).

The effects of excessive catecholamines on metabolism and hemodynamics have been widely studied (Lambert et al., 2013; Mancia et al., 2007; Young \& Macdonald, 1992). Hypertension and hypermetabolism characterized by increased lipolysis and glycogenolysis are among the direct effects caused by adrenoceptor stimulation in metabolically active organs and tissues (Petrak et al., 2013). Indirect effects include abnormal glucose metabolism and overproduction of proinflammatory cytokines such as IL-1, IL-6 and TNF-alpha (Morley, Thomas, \& Wilson, 2006; Mraz et al., 2011; Schols, Buurman, Staal van den Brekel, Dentener, \& Wouters, 1996; Tisdale, 2009). Both the direct and indirect effects of excessive catecholamines dispose individuals for developing the metabolic syndrome, which increases the risk of diabetes mellitus type 2 five times and the risk of CVD and cardiovascular death three times (Nakajima et al., 2013; Stern, Williams, Gonzalez-Villalpando, Hunt, \& Haffner, 2004). Furthermore, p-NE has been found to be an independent predictor of prognosis in patients with congestive heart failure (Francis et al., 1993).

Altered levels of p-NE in depressive illness have been the topic of a limited number of studies which, however, yield inconclusive results. The studies are considered inconclusive due to methodological differences and small sample sizes. To the best of our knowledge, no studies have previously examined associations between potentially altered $\mathrm{NE}$ metabolism and risk factors of CVD in a large group of non-medicated patients with major depression.

The aim of the present study was, firstly, to investigate if p-NE levels differ between patients with major depression and healthy controls. Secondly, the study sought to assess the associations between p-NE and metabolic variables in all participants. The third and final aim of the study was to assess if the associations between p-NE and metabolic variables are influenced by disease status (depression vs. healthy).

\section{Methods}

\subsection{Study design}

The current study was conducted as a matched case-control study with a case group of 108 patients diagnosed with major depression and a matched control group of 44 non-depressed healthy subjects.

\subsection{Study participants}

We reanalysed the data from 108 depressed patients, who participated in a previous randomized clinical trial (the DEMO-II trial) that evaluated the antidepressant properties of aerobic exercise (Krogh, Videbech, Thomsen, Gluud, \& Nordentoft, 2012). Eligible participants were men and women between 18 and 60 years of age, referred from a clinical setting by a physician or a psychologist, and with a diagnosis of major depression (DSM-IV) based on the Danish version of the Mini International Neuropsychiatric Interview (MINI) (Bech, Andersen, \& Schütze, 1999). All included depressed participants signed the informed consent statement and scored above 12 on the Hamilton Depression Rating Scale (HAM-D17) (Hamilton, 1960). Exclusion criteria were current drug abuse, antidepressant medication within the last two months, current psychotherapeutic treatment, contraindications to physical exercise, regular recreational exercise over $1 \mathrm{~h}$ per week, suicidal behaviour according to the HAM-D17 (item 3, $\geq 2$ ), pregnancy, or current/previous psychotic or manic symptoms. Out of the 227 potential participants that were referred to the trial site, 112 persons were excluded. The two primary reasons for exclusion were failure to meet the study criteria for depression $(\mathrm{n}=32)$ and declining participation $(\mathrm{n}=32)$. Data from 7 of the depressed participants were not available for assessment due to technical problems, thus 108 participants constitute the group of depressed patients for the current study. Healthy controls $(n=44)$ were recruited through the media and group matched to the patients with regard to sex, age, and body mass index (BMI). The healthy controls were free of any current or previous psychiatric diseases assessed by the MINI (Bech et al., 1999). Evaluation of patients and healthy controls was commenced in parallel.

\subsection{Procedures}

\subsubsection{Examination}

All participants met at the research department between 8:00 and 10:00 a.m. and had beforehand been instructed to refrain from eating and drinking anything except water beginning from midnight prior to the examination day. Furthermore, participants had been instructed not to perform any type of strenuous physical activity prior to the examination. At first, participants were weighed using an electronic scale (Sohnle Medicals, Type 7700, Backnang, Germany). Afterwards, following five uninterrupted minutes of rest in a sitting position, blood pressure was measured using a certified digital blood pressure monitor (Omron M6, Omron Healthcare co. LTD, Kyoto, Japan). Three measurements were performed on each participant, and the average blood pressure was reported. After another $5 \mathrm{~min}$ of rest in a sitting position, blood samples were collected through an indwelling venous catheter placed in an antecubital vein. Immediately, the samples were centrifuged at room temperature and stored at $-80^{\circ} \mathrm{C}$ with light protection until being analysed in the laboratory by automated procedures.

\subsubsection{Norepinephrine assay}

Quantification of p-NE levels was performed with enzyme-linked immunosorbent assay (ELISA) kits from Whuan EIAab Science Co., LTD, A1710 Guangguguoji East Lake Hi-Tech Zone Wuhan 430074 China. The same batch number was used for the entire experiment. The determination was processed according to the manufacturer's specifications, and the absorbance was immediately measured at $450 \mathrm{~nm}$ (EL 800 Universal Microplate reader, Bio-Tek instruments, INC). The standard curves and the samples (blinded) were run in duplicate. Two controls were included on each plate. The standard curves ranged from 31.2 to $2000 \mathrm{pg} / \mathrm{ml} \mathrm{NE}$. The samples were diluted 10 times to be within the range of the standard curve. The intra-assay coefficient of variance for the present study was $7.6 \%$. Therefore, duplicate determinations of absorbency with an intra-assay variance above $7.6 \%$ were determined again another day. The average of the duplicates was used in the statistical analyses.

\subsection{Outcome measures}

\subsubsection{Primary outcome}

P-NE was measured as stated in Section 2.3.2.

\subsubsection{Secondary outcomes}

With the purpose of assessing associations between p-NE and metabolism, all participants had the following variables measured: 1) Mean arterial blood pressure (MAP) (measured as stated in Section 2.3), 2) Plasma lipids: HDL, LDL, triglycerides and cholesterol, 3) Plasma glucose, 4) Plasma insulin, 5) Insulin sensitivity (measured by quantitative insulin sensitivity check index (QUICKI)), 6) BMI and waist circumference (used as measures of general and abdominal obesity, respectively), 7) Inflammatory markers: Plasma high-sensitivity CRP 
(hsCRP) and plasma interleukin 6 (IL-6). Measurement of plasmahsCRP was performed using the Immulite 2000 immunoassay system (Siemens, USA). Plasma levels of IL- 6 were determined by the Human IL-6 High Sensitivity ELISA kit (eBioscience, Bender MedSystems $\mathrm{GmbH}$, Austria).

\subsection{The role of confounders}

The potential source of error from confounding has been controlled for through the study design and analytical stages. Confounders considered to be of high relevance to the current study include smokinghabits, dietary intake, physical exercise, gender, age and medications (alpha-blockers, antihypertensives, MAO-inhibitors and paracetamol). Cigarette smoking leads to increased release of catecholamines both locally from neurons and systemically from the adrenal gland. The mechanisms responsible are the sympathomimetic effects of nicotine, and the results are, among others, increased levels of p-NE (Services, 2010). Influence of dietary intake was minimized by instructing patients to fast from midnight prior to test day. Since vigorous physical exercise affects the accuracy of any catecholamine tests, participants were advised to refrain from engaging in any type of strenuous physical activity prior to the examination as well. It has been demonstrated several times that age and p-NE are positively correlated. For example, one study found a linear relationship $(r=0.39)$ (Izzo, Smith, Larrabee, \& Kallay, 1987), which exerts a potential confounding effect on the studied associations between p-NE and metabolism. In analyses of previous studies, the use of tricyclic antidepressants has been found to affect p-NE levels (Spasojevic, Gavrilovic, Kovacevic, \& Dronjak, 2009; Veith et al., 1994). However, use of antidepressants was among the exclusion criteria, and the confounding influence of this variable is therefore irrelevant to the current study.

\subsection{Approvals}

The protocol was approved by the local ethics committee (H-A2008-046) and the Danish Data Protection Agency (J.nr.2008-412354). Verbal and written informed consent was obtained from all participants involved in the trial.

\subsection{Statistics}

To determine whether p-NE levels differ based on disease status (depressed versus healthy) we used an independent $t$-test and chisquare test with the dependent variable being $\mathrm{p}$-NE and the independent variable being disease status. Due to deviations from normal distribution, (ln) p-norepinephrine was used. Linear regression was used to analyse the association between $\mathrm{p}$-NE and metabolic variables (e.g. blood pressure, glucose, lipids and BMI). As part of this analysis, we constructed three models that differ in the amount of confounding variables adjusted for. Model 1 is univariate; model 2 is adjusted for age, gender, and smoking; model 3 is adjusted for age, gender, smoking, alcohol, BMI and drugs (Cholesterol, LDL, HDL were adjusted for lipidlowering drugs; MAP was adjusted for antihypertensive drugs; Glucose, Insulin, QUICKI were adjusted for glucose lowering drugs). All statistical tests were two-sided and SPSS version 22.0 was used for analysis. Finally, an interaction term was used to examine if the associations between $\mathrm{p}$-NE and metabolic variables were influenced by disease status (e.g. if the effects of p-NE on lipids or glucose depends on disease status). Pearson's correlations were calculated in order to determine the strength of associations between (ln) p-NE and gender, (ln) p-NE and daily smoking as well as (ln) p-NE and age. P-values less than or equal to 0.05 were considered significant.
Table 1

Clinical and demographic characteristics.

\begin{tabular}{|c|c|c|c|}
\hline & $\begin{array}{l}\text { Patients } \\
N=108\end{array}$ & $\begin{array}{l}\text { Healthy controls } \\
N=44\end{array}$ & $P$ value \\
\hline Female, n (\%) & $70(64.8)$ & $30(682)$ & 0.69 \\
\hline Age, years & $41.6(11.5)$ & $38.6(12.5)$ & 0.15 \\
\hline Smoking, daily, n (\%) & $45(41.7)$ & $6(13.6)$ & 0.001 \\
\hline Alcohol, n (\%) & $12(11.1)$ & $3(6.8)$ & 0.42 \\
\hline \multicolumn{4}{|l|}{ Drugs } \\
\hline Recreational drugs $>1$ month & 8 & 2 & 0.52 \\
\hline Alfa-blockers & 0 & 0 & 1.0 \\
\hline Antihypertensive drugs & 3 & 1 & 0.86 \\
\hline Lipid lowering drugs & 3 & 0 & 0.56 \\
\hline Paracetamol & 3 & 0 & 0.56 \\
\hline Glucose lowering drugs & 1 & 0 & 1.0 \\
\hline Beta-2-agonists & 5 & 2 & 1.0 \\
\hline \multicolumn{4}{|l|}{ Depression } \\
\hline HAM-D17 & $18.8(3.8)$ & $1.1(1.6)$ & $<0.001$ \\
\hline HAM-A14 & $17.7(5.6)$ & $1.0(1.5)$ & $<0.001$ \\
\hline Recurrent depression, $\mathrm{n}(\%)$ & $56(51.9)$ & N/A & N/A \\
\hline \multicolumn{4}{|l|}{ Somatic } \\
\hline Weight, kg & $78.3(20.3)$ & $77.0(19.3)$ & 0.71 \\
\hline $\mathrm{BMI}, \mathrm{kg} / \mathrm{m}^{2}$ & $26.6(6.0)$ & $26.0(6.6)$ & 0.60 \\
\hline Waist circumference, $\mathrm{cm}$ & $90.1(16.5)$ & $85.2(11.8)$ & 0.08 \\
\hline Creatinine, $\mu \mathrm{mol} / \mathrm{L}$ & $66.8(12.6)$ & $66.0(11.1)$ & 0.73 \\
\hline Systolic bp, mmHg & $121.8(17.0)$ & $119.5(12.2)$ & 0.43 \\
\hline Diastolic bp, $\mathrm{mmHg}$ & $81.5(11.8)$ & $79.4(10.2)$ & 0.31 \\
\hline \multicolumn{4}{|l|}{ Inflammation } \\
\hline hsCRP, $\mathrm{mg} / \mathrm{l}$ & $2.5(3.7)$ & $1.3(1.6)$ & 0.007 \\
\hline Interleukin $6, \mathrm{pg} / \mathrm{ml}$ & $2.0(1.8)$ & $1.5(1.4)$ & 0.13 \\
\hline \multicolumn{4}{|l|}{ Metabolism } \\
\hline Cholesterol, mmol/1 & $5.2(1.1)$ & $4.9(0.9)$ & 0.15 \\
\hline $\mathrm{LDL}, \mathrm{mmol} / \mathrm{l}$ & $3.1(1.0)$ & $2.8(0.8)$ & 0.04 \\
\hline Triglycerides, mmol/l & $1.4(0.7)$ & $1.0(0.6)$ & 0.005 \\
\hline $\mathrm{HDL}, \mathrm{mmol} / \mathrm{l}$ & $1.4(0.4)$ & $1.6(0.4)$ & 0.004 \\
\hline Insulin, pmol/1 & $68.9(54.1)$ & $56.2(38.3)$ & 0.11 \\
\hline Glucose, mmol/l & $5.1(0.7)$ & $5.0(0.6)$ & 0.58 \\
\hline QUICKI & $0.82(1.5)$ & $0.67(0.12)$ & 0.56 \\
\hline
\end{tabular}

Data are presented with estimated mean (SD) unless stated otherwise. Abbreviations: BMI-Body mass index; HAM-D17-Hamilton Depression Scale, 17 items; HAM-A14-Hamilton Anxiety Scale, 14 items; bp-blood pressure; hsCRP-high sensitivity CRP; QUICKI - Quantitative Insulin Sensitivity Check Index.

\section{Results}

\subsection{Baseline data}

The 108 patients with depression and the 44 healthy controls were comparable with respect to baseline demographic and clinical characteristics, as illustrated in Table 1. The mean age of the depressed group was 41.6 years, and the proportion of female participants was $70 / 108$ (65\%). The group of healthy controls had a mean age of 38.6 years and consisted of $30 / 44(68 \%)$ female participants. The mean HAM-D17 was 18.8 points for the depressed patients, indicating mild to moderate depression, compared to a mean HAM-D17 of 1.1 points in the group of healthy controls $(\mathrm{p}<0.001)$. In the group of depressed patients, 56/108 (52\%) had recurrent depression, while 52/108 (48\%) were diagnosed with first episode depression. Daily smoking was more common in the group of depressed patients compared to healthy controls $(41.7 \%$ versus $13.6 \%, \mathrm{p}<0.001)$.

Statistically significant univariate differences in triglycerides, LDL and HDL were found between patients with major depression and healthy controls (shown in Table 1). Compared to healthy controls, triglycerides and LDL were elevated in depressed patients, while HDL levels were lowered. Another finding amongst the investigated metabolic variables was high abdominal waste circumference in depressed compared to healthy controls $(\mathrm{p}=0.08)$. 


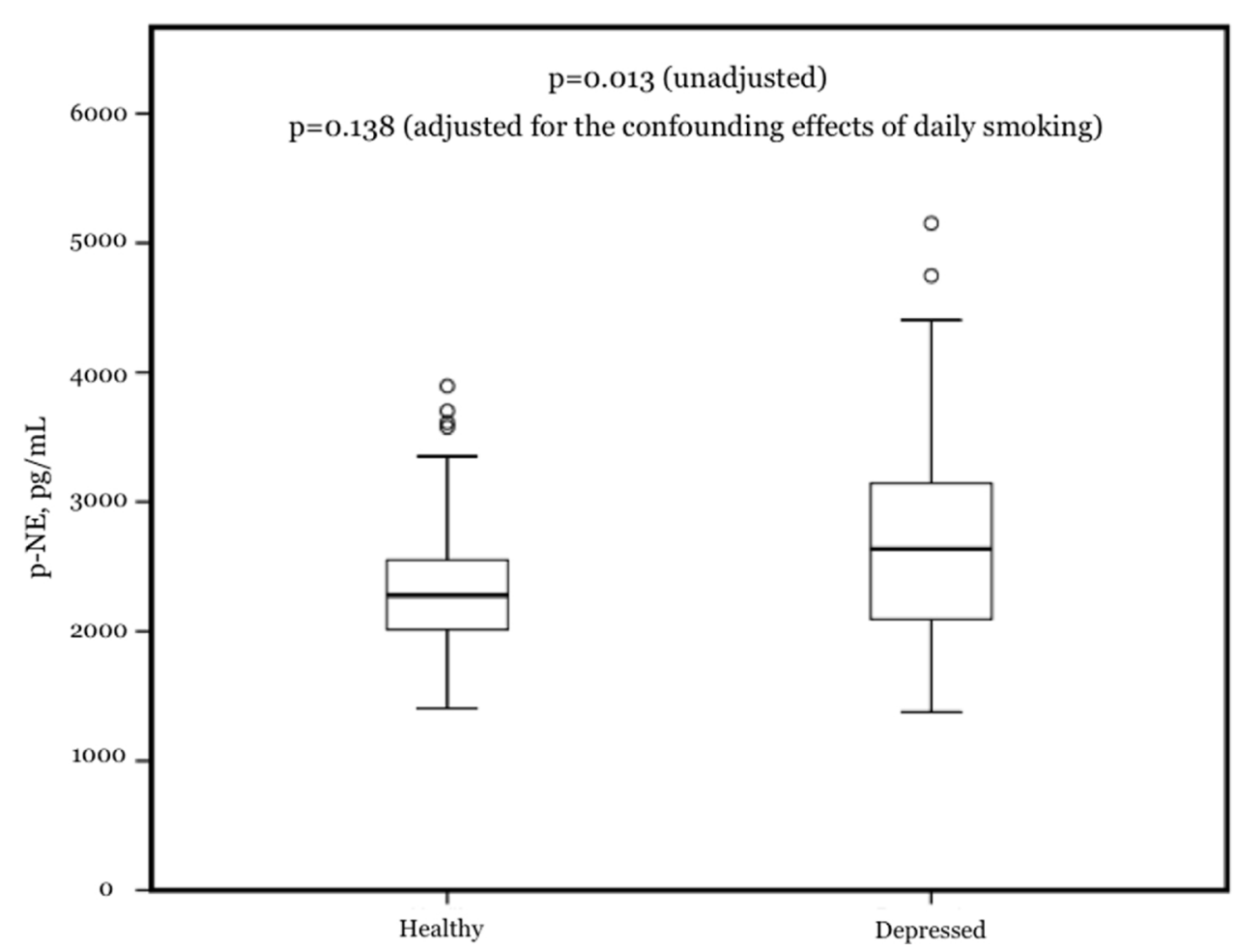

Fig. 1. Box plot showing plasma norepinephrine levels in healthy controls and patients with major depression before adjusting for the confounding effects of daily smoking.

\subsection{Primary outcome - p-NE at rest}

In patients diagnosed with major depression, the median level of p$\mathrm{NE}(2636 \mathrm{pg} / \mathrm{ml}$, IQR 2094-3143) was higher $(\mathrm{p}=0.013)$ compared to healthy controls (2279 pg/ml, IQR 2007-2562), as illustrated in Fig. 1. However, the difference between p-NE levels was non-significant when adjusted for the confounding effects of daily smoking $(\mathrm{p}=0.138)$.

\subsection{Secondary outcomes - the association between p-NE and metabolic variables}

Associations were found between p-NE and plasma lipids (cholesterol, LDL, HDL and triglycerides, all p-values < 0.001), p-NE and BMI ( $\mathrm{p}<0.001$ ), $\mathrm{p}-\mathrm{NE}$ and waist circumference $(\mathrm{p}<0.005$ ), $\mathrm{p}-\mathrm{NE}$ and MAP ( $<<0.001$ ), p-NE and p-insulin ( $<0.001$ ), p-NE and QUICKI ( $\mathrm{p}<0.001$ ), as well as between $\mathrm{p}-\mathrm{NE}$ and inflammatory markers (hsCRP and IL-6, p $<0.008$ and $\mathrm{p}=0.05$, respectively). No association was observed between $\mathrm{p}$-NE and p-glucose $(\mathrm{p}=0.14)$ after adding sex, alcohol, BMI and drugs to the multivariable logistic regression analysis. As illustrated in Table 2, the investigated associations between p-NE and metabolic variables have all been adjusted for age, sex, smoking, alcohol, BMI and drugs in model 3 (LDL and HDL have been adjusted for lipid-lowering drugs; MAP have been adjusted for antihypertensive drugs; Glucose, Insulin and QUICKI were adjusted for glucose lowering drugs).

\subsection{The influence of disease status}

We added the interaction term disease status (p-NE $\mathrm{x}$ disease status) to the regression model and found all associations to be independent of disease status (interaction term p-values were $\geq 0.10$ as illustrated in Table 2).

\subsection{Confounders}

The Pearson's correlation between (ln) p-NE and gender (women vs. male) was 0.05 ( $\mathrm{p}=0.50$ ), between (ln) p-NE and daily smoking (no vs. yes) $0.21(\mathrm{p}=0.01)$ and between $(\mathrm{ln}) \mathrm{p}-\mathrm{NE}$ and age $0.21(\mathrm{p}=0.001)$.

\section{Discussion}

The present study found that levels of plasma-NE were significantly increased in patients with major depression compared to healthy controls. However, the difference between the two groups was non-significant when adjusted for differences in smoking habits. This can be explained by the fact that daily smoking was significantly more common in the group of depressed patients compared to the group of healthy controls $(41.7 \%$ versus $13.6 \%$, $\mathrm{p}<0.001)$. Meanwhile, we did find associations between $\mathrm{p}-\mathrm{NE}$ and the following metabolic variables: P-lipids, BMI, waist circumference, MAP, insulin, QUICKI and inflammatory markers (hsCRP and IL-6). All associations were independent of disease status (depression vs. healthy).

A limitation of the present study is that it is based on a clinical trial conducted with the intention of a different primary research purpose. Furthermore, levels of p-NE measured in all participants were higher than expected. However, the data are consistent, the intra-assay variability is low, the results do not contradict previous findings, and the laboratory personnel were blinded to group status during analysis. Additionally, the levels of p-NE have been studied and confirmed by the use of high performance liquid chromatography on few randomly selected samples. A more general factor to take into account when studying NE metabolism is the uncertainty associated with the extent to which plasma concentrations reflect overall activity of the SNS versus regional sympathetic outflow. The fact that p-NE levels change not only because of changes in sympathetic nerve firing, but also as a consequence of changes in plasma clearance is also important.

To the best of our knowledge, no previous studies have similarly examined NE metabolism and associations with risk factors of CVD in a large group of non-medicated patients with major depression. Potential altered levels of p-NE in subtypes of depressive illness have been the topic of a limited number of studies. One previous study comparing levels of $\mathrm{p}-\mathrm{NE}$ in depressed $(\mathrm{n}=50)$ and non-depressed $(\mathrm{n}=39)$ 
Table 2

The association between plasma norepinephrine and inflammatory and metabolic variables.

\begin{tabular}{|c|c|c|c|c|}
\hline & Model 1 & Model 2 & Model 3 & Interaction term \\
\hline \multicolumn{5}{|l|}{ Metabolism } \\
\hline Cholesterol & $0.11(0.07$ to $0.14 ; \mathrm{p}<0.001)$ & $1.36(0.74$ to $1.97 ; \mathrm{p}<0.001)$ & $1.57(0.91$ to $2.23 ; \mathrm{p}<0.001)$ & 0.16 \\
\hline LDL & $0.12(0.08$ to $0.17 ; \mathrm{p}<0.001)$ & $1.25(0.70$ to $1.80 ; \mathrm{p}<0.001)$ & $\begin{array}{l}1.43(0.84 \text { to } 2.03 \\
p<0.001)\end{array}$ & 0.31 \\
\hline HDL & $-0.18(-0.30$ to $-0.06 ; p=0.003)$ & $-0.38(-0.61$ to $-0.15 ; \mathrm{p}=0.001)$ & $\begin{array}{l}-0.32(-0.57 \text { to }-0.07 \\
\mathrm{p}<0.01)\end{array}$ & 0.10 \\
\hline Triglycerides & $0.20(0.15$ to $0.25 ; \mathrm{p}<0.001)$ & $0.18(0.13$ to $0.23 ; \mathrm{p}<0.001)$ & $\begin{array}{l}1.31(0.87 \text { to } 1.76 \\
\mathrm{p}<0.001)\end{array}$ & 0.65 \\
\hline BMI & 8.92 (5.45 to $12.45 ; \mathrm{p}<0.001$ & $8.94(5.23$ to $12.65 ; \mathrm{p}<0.001)$ & $\begin{array}{l}8.95(5.23 \text { to } 12.67 \\
p<0.001)\end{array}$ & 0.57 \\
\hline Waist circumference & 27.51 (19.06 to $35.95 ; \mathrm{p}<0.001)$ & 24.24 (15.70 to $32.79 ; \mathrm{p}<0.001)$ & $\begin{array}{l}8.83(2.65 \text { to } 15.00 \\
\mathrm{p}<0.005)\end{array}$ & 0.63 \\
\hline MAP & 20.81 (14.12 to $27.50 ; \mathrm{p}<0.001)$ & 15.36 (8.79 to $21.93 ; \mathrm{p}<0.001)$ & $\begin{array}{l}11.81(4.78 \text { to } 18.85 \\
\mathrm{p}<0.001)\end{array}$ & 0.96 \\
\hline Glucose & $0.69(0.26$ to $1.11 ; \mathrm{p}=0.002)$ & $0.47(0.03$ to $0.91 ; \mathrm{p}=0.04)$ & $\begin{array}{l}0.34(-0.11 \text { to } 0.78 \\
\mathrm{p}=0.14)\end{array}$ & 0.09 \\
\hline (ln) Insulin & $1.13(0.70$ to $1.55 ; \mathrm{p}<0.001)$ & $1.22(0.75$ to $1.68 ; \mathrm{p}<0.001)$ & $\begin{array}{l}0.39(0.21 \text { to } 0.56 \\
\mathrm{p}<0.001)\end{array}$ & 0.69 \\
\hline QUICKI & $-0.12(-0.94$ to $0.69 ; \mathrm{p}=0.76)$ & $-0.27(-1.15$ to $0.61 ; \mathrm{p}=0.54)$ & $-0.25(-0.39$ to $-0.12 ; \mathrm{p}<0.001)$ & 0.86 \\
\hline \multicolumn{5}{|l|}{ Inflammation } \\
\hline hsCRP & $\begin{array}{l}4.33(2.50 \text { to } 0.69 \\
\mathrm{p}<0.001)\end{array}$ & $\begin{array}{l}4.27(2.31 \text { to } 6.23 \\
\mathrm{p}<0.001)\end{array}$ & $\begin{array}{l}2.72(0.71 \text { to } 4.73 \\
\mathrm{p}<0.008)\end{array}$ & 0.13 \\
\hline (ln) IL-6 & $\begin{array}{l}0.81(0.40 \text { to } 1.22 \\
\mathrm{p}<0.001)\end{array}$ & $\begin{array}{l}0.58(0.17 \text { to } 0.99 \\
\mathrm{p}=0.006)\end{array}$ & $\begin{array}{l}0.43(-0.01 \text { to } 0.87 \\
p=0.05\end{array}$ & 0.83 \\
\hline
\end{tabular}

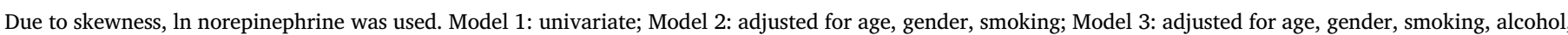

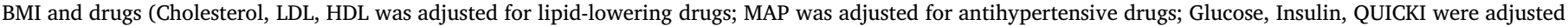
for glucose lowering drugs).

patients with coronary heart disease (CHD) found no difference in p-NE between the groups (Carney et al., 1999). Other results of that study were elevated resting heart rate $(\mathrm{p}=0.005)$ and exaggerated heart rate response to orthostatic challenge in depressed subjects compared to non-depressed. These findings reflect altered autonomic activity and therefore, the lack of difference in $\mathrm{p}-\mathrm{NE}$ is unexpected. The discrepancy may relate to lack of control for confounding variables. Alternatively, reduced vagal tone rather than increased SNS activity may have been the cause of elevated heart rates in the depressed subjects with CHD. A different study $(\mathrm{n}=17)$ found that the median level of $\mathrm{p}$-NE was elevated in a mixed group of patients with psychotic depression $(n=4)$ and melancholia $(n=6)$ compared to patients $(n=7)$ diagnosed with other subtypes of depressive illness (Kelly \& Cooper, 1998). Similarly, another study found elevated levels of p-NE in a group of patients with psychotic depression $(n=9)$ compared to a group of non-psychotic depressed patients $(n=69)$ (Goekoop, de Winter, Wolterbeek, Van Kempen, \& Wiegant, 2012). Findings of increased p-NE in subgroups of depressive illness do not conflict with the results of the current study or the study of depressed patients with CHD since unidentified subgroups with excessive p-NE may be present in these studies as well.

Finally, based on the present as well as previous studies it can be suggested that $\mathrm{p}-\mathrm{NE}$ is not generally elevated in patients with major depression. However, data indicate that levels of $\mathrm{p}-\mathrm{NE}$ are elevated in subgroups of depressed patients (e.g. patients with psychotic depression).

It is widely recognized that stress induced NE release stimulates beta-adrenoceptors resulting in lipolysis of triglyceride stores in metabolically active organs and tissues (Ward et al., 1994). At very low concentrations however, NE stimulates anti-lipolysis through alpha-2adrenoceptors modulating resting adipocyte activity (Bernlohr, 2002). Consistent with the results of the present study, the relative contributions of the two opposing pathways are therefore determined by levels of p-NE. Furthermore, the finding of p-NE being associated with p-lipids (cholesterol, LDL, HDL and triglycerides) is in line with results of previous studies on the role of catecholamines in the regulation of lipid metabolism (O'Donnell et al., 1988; Petrak et al., 2013). The observed direct relationship between p-NE, cholesterol, LDL and triglycerides as well as the inverse relationship between p-NE and HDL suggest that increased SNS activity may increase the risk of CVD (Mottillo et al., 2010).

Another area of interest to the current study is how the autonomic nervous system and its sympathetic arm play a role in the regulation of blood pressure. Current studies in patients with pheochromocytoma suggest that high levels of p-NE strongly correlate with hypertension (Zuber, Kantorovich, \& Pacak, 2011a; Zuber, Kantorovich, \& Pacak, 2011b). Similarly, a study of patients not diagnosed with pheochromocytoma discovered that levels of p-NE were significantly elevated $(517 \pm 27$ versus $344 \pm 37 \mathrm{pg} / \mathrm{mL} ; \mathrm{P}=0.004)$ in hypertensive subjects $(n=17)$ compared to normotensive subjects $(n=16)$ (Penesova et al., 2008). Consistent with these previous results, an association between p-NE and MAP was found in the present study. Presumably, excess NE is stored in the axon terminals of the sympathetic ganglia and released with activation of the SNS causing continuous vasoconstriction through $\alpha_{1}$-receptor stimulation (Zuber et al., 2011a, 2011b). Further contributing to increases in blood pressure, catecholamines stimulate $\beta_{1}$-receptors on the surface of juxtaglomerular cells leading to the release of renin (Aldehni et al., 2011). Evidence exist, that a number of non or minimally treated patients with excessive p-NE are asymptomatic (Krause, Reinhardt, \& Kruse, 1988). In line with this finding, numerous studies have reported significant $\alpha$ - and $\beta$ - adrenoceptor desensitization in humans and animal models, which may play an important role in preventing the symptoms of elevated plasma catecholamines, i.e. increased blood pressure (Greenacre \& Conolly, 1978; Jones, Hamilton, Whyte, Elliott, \& Reid, 1985; Tsujimoto, Honda, Hoffman, \& Hashimoto, 1987).

Excessive catecholamines also results in abnormal glucose metabolism (Barth et al., 2007). Specifically, catecholamines increase metabolism by increasing oxygen consumption and glucose oxidation (Ensinger, Weichel, Lindner, Grunert, \& Ahnefeld, 1993; Hoeks et al., 2003). In line with this, studies examining energy metabolism in patients with pheochromocytoma found HbA1c and resting energy expenditure to be significantly decreased after adrenalectomy (Okamura et al., 2015; Petrak et al., 2013). However, no association between p-NE and p-glucose was found in the present study. 
In terms of the observed positive correlation between $\mathrm{p}-\mathrm{NE}$ and insulin, similar results have been reported previously (Landsberg, 1996). A study investigating the association between insulin and SNS activity found elevated levels of urinary-NE in subjects with hyperinsulinemia compared to non-hyperinsulinemic subjects (Troisi et al., 1991). In these studies, increased p-NE may be caused by insulin mediated excitation of the SNS to increase metabolic rate and restore energy balance in hyperinsulinemic subjects. The mechanisms and sites of such potential insulin induced sympathetic excitation remain uncertain, but the hypothesis does not conflict with the proved inhibiting effects of NE on insulin release in pancreatic $\beta$-cells (Yajima et al., 2001). In addition, a negative correlation between p-NE and insulin sensitivity (measured as QUICKI) was found in the present study. This is consistent with results of previous studies, one of which found that catecholamines stimulate adipocyte secretion of tumor necrosis factor- $\alpha$ (TNF- $\alpha$ ) (Fu et al., 2007). By directly inhibiting the actions of insulin, TNF- $\alpha$ may contribute to the pathogenesis of catecholamine induced decreased insulin sensitivity (Borst, 2004). Concerning the association between $\mathrm{p}$-NE and inflammation, it has been suggested several times that excessive production of catecholamines leads to low grade chronic inflammation (Irwin, 2002; Petrak et al., 2010; Zelinka et al., 2007). Consistently, an association between p-NE and proinflammatory markers (hsCRP and IL-6) was found in the current study. Direct effects of $\mathrm{p}$-NE stimulation of $\beta_{2}$-receptors on T-lymphocytes include altered $\mathrm{T}$ cell proliferation, $\mathrm{T}$-cell differentiation, cytokine production and $\mathrm{T}$ helper-cell mediated antibody production (Sanders, 2012). Furthermore, the density of lymphocyte surface $\beta_{2}$-receptors has been shown to be reversibly decreased in patients with chronic catecholamine excess (Cases et al., 1995). An inverse relation between hsCRP and the generation of basal nitric oxide links elevated levels of hsCRP to endothelial dysfunction and possibly cardiac disease (Cleland et al., 2000). Elevated levels of hsCRP and pro-inflammatory cytokines have previously been associated with cardiac disease in general and, interestingly, in depressed subjects (Halaris, 2013).

To the best of our knowledge, this is the first study to examine associations between potentially altered NE metabolism and risk factors of CVD in a large group of non-medicated patients with major depression. In summary, we found that elevated levels of p-NE observed in patients with major depression were attributable to daily smoking, rather than to the depressive disorder. This finding suggests that $\mathrm{p}-\mathrm{NE}$ does not constitute a relevant marker of depression, but further studies are needed to confirm the results. Additionally, our analyses of associations between $\mathrm{p}-\mathrm{NE}$ and metabolic variables indicate that excessive levels of p-NE may increase risk factors for CVD in both depressed and non-depressed subjects. This is interesting from a clinical point of view, since affected individuals may benefit from simple and inexpensive therapies that influence sympathetic activity. Relevant examples of such potentially preventive treatments include lifestyle changes (e.g. related to cigarette smoking, alcohol use, diet and exercise) as well as medications (e.g. alpha blockers, beta blockers, centrally acting sympatoinhibitory agents and selective serotonin reuptake inhibitors (SSRIs)). Interestingly, one large clinical trial has found that the centrally acting imidazoline receptor agonist moxonidine can safely and effectively be used to treat patients with uncontrolled essential hypertension and the metabolic syndrome (Chazova \& Schlaich, 2013). Potentially, patients with excessive levels of p-NE may experience additional benefits to such therapies targeting underlying sympathetic pathophysiologic pathways in regards to the associated metabolic disturbances and increased risk factors for CVD described in the present study. A different study has found that treating patients with major depression with SSRIs may reduce sympathetic activity in a manner likely to reduce cardiac risk (Barton et al., 2007). Future research should be designed to clarify whether levels of $\mathrm{p}-\mathrm{NE}$ are elevated in specific subgroups of depressed patients (i.e. patients with co-occurring stress disorders and patients with psychotic depression) and thus provide a stronger rationale for therapeutic approaches.

\section{Conflict of interest}

None. All authors report no biomedical financial interest or potential conflicts of interest.

\section{Approvals}

The protocol was approved by the local ethics committee (H-A2008-046) and the Danish Data Protection Agency (J.nr.2008-412354). Verbal and written informed consent was obtained from all participants involved in the trial.

\section{Role of funding source}

Funding support for this study was provided by Trygfonden, Nordea Danmark fonden, Aase og Ejnar Danielsens Fond. The study's funding sources had no role in the study design, collection, analysis, interpretation of data, in writing of the report, or in the decision to submit the paper for publication. The corresponding author had full access to all the data and had final responsibility for the decision to submit for publication.

\section{References}

Aldehni, F., Tang, T., Madsen, K., Plattner, M., Schreiber, A., Friis, U. G., et al. (2011). Stimulation of renin secretion by catecholamines is dependent on adenylyl cyclases 5 and 6. Hypertension, 57, 460-468.

Barth, E., Albuszies, G., Baumgart, K., Matejovic, M., Wachter, U., Vogt, J., et al. (2007). Glucose metabolism and catecholamines. Critical Care Medicine, 35, S508-518.

Barton, D. A., Dawood, T., Lambert, E. A., Esler, M. D., Haikerwal, D., Brenchley, C., et al. (2007). Sympathetic activity in major depressive disorder: Identifying those at increased cardiac risk? Journal of Hypertension, 25, 2117-2124.

Bech, P., Andersen, G., \& Schütze, T. (1999). Mini internationalt neuropsykiatrisk interview. Danish version 5.0.0.

Bernlohr, D. A. (2002). Adipose tissue and lipid metabolism. Elsevier Science.

Bissette, G., Klimek, V., Pan, J., Stockmeier, C., \& Ordway, G. (2003). Elevated concentrations of CRF in the locus coeruleus of depressed subjects. Neuropsychopharmacology, 28, 1328-1335.

Borst, S. E. (2004). The role of TNF-alpha in insulin resistance. Endocrine, 23, 177-182.

Carney, R. M., Blumenthal, J. A., Stein, P. K., Watkins, L., Catellier, D., Berkman, L. F., et al. (2001). Depression, heart rate variability, and acute myocardial infarction. Circulation, 104, 2024-2028.

Carney, R. M., Freedland, K. E., Veith, R. C., Cryer, P. E., Skala, J. A., Lynch, T., et al. (1999). Major depression, heart rate, and plasma norepinephrine in patients with coronary heart disease. Biological Psychiatry, 45, 458-463.

Cases, A., Bono, M., Gaya, J., Jimenez, W., Calls, J., Esforzado, N., et al. (1995). Reversible decrease of surface beta 2-adrenoceptor number and response in lymphocytes of patients with pheochromocytoma. Clinical and Experimental Hypertension, $17,537-549$.

Chazova, I., \& Schlaich, M. P. (2013). Improved hypertension control with the imidazoline agonist moxonidine in a multinational metabolic syndrome population: Principal results of the MERSY study. International Journal of Hypertension541689.

Cleland, S. J., Sattar, N., Petrie, J. R., Forouhi, N. G., Elliott, H. L., \& Connell, J. M. (2000) Endothelial dysfunction as a possible link between C-reactive protein levels and cardiovascular disease. Clinical Science, 98, 531-535.

Cuijpers, P., \& Smit, F. (2002). Excess mortality in depression: A meta-analysis of community studies. Journal of Affective Disorders, 72, 227-236.

Davidson, J. S. K. W. (2013). Depression and cardiovascular diseases. The oxford handbook of depression and comorbidity287-290.

DiVincenzo, L., Reber, M., Perera, V., \& Chilian, W. M. (2014). Connecting the dots establishing causality between chronic stress, depression, and cardiovascular disease. Journal of Applied Physiology, 117, 957-958.

Ensinger, H., Weichel, T., Lindner, K. H., Grunert, A., \& Ahnefeld, F. W. (1993). Effects of norepinephrine, epinephrine, and dopamine infusions on oxygen consumption in volunteers. Critical Care Medicine, 21, 1502-1508.

Ferrari, A. J., Somerville, A. J., Baxter, A. J., Norman, R., Patten, S. B., Vos, T., et al. (2013). Global variation in the prevalence and incidence of major depressive disorder: A systematic review of the epidemiological literature. Psychological Medicine, 43, 471-481.

Francis, G. S., Cohn, J. N., Johnson, G., Rector, T. S., Goldman, S., \& Simon, A. (1993). Plasma norepinephrine, plasma renin activity, and congestive heart failure. Relations to survival and the effects of therapy in V-HeFT II. The V-HeFT VA Cooperative Studies Group. Circulation, 87, 40-48.

Fu, L., Isobe, K., Zeng, Q., Suzukawa, K., Takekoshi, K., \& Kawakami, Y. (2007). betaadrenoceptor agonists downregulate adiponectin, but upregulate adiponectin receptor 2 and tumor necrosis factor-alpha expression in adipocytes. European Journal of Pharmacology, 569, 155-162.

Goekoop, J. G., de Winter, R. F., Wolterbeek, R., Van Kempen, G. M., \& Wiegant, V. M. 
(2012). Increased plasma norepinephrine concentration in psychotic depression. Therapeutic Advances in Psychopharmacology, 2, 51-63.

Goldstein, D. S., McCarty, R., Polinsky, R. J., \& Kopin, I. J. (1983). Relationship between plasma norepinephrine and sympathetic neural activity. Hypertension (Dallas, Tex : 1979), 5, 552-559.

Grassi, G., \& Esler, M. (1999). How to assess sympathetic activity in humans. Journal of Hypertension, 17, 719-734.

Greenacre, J. K., \& Conolly, M. E. (1978). Desensitization of the beta-adrenoceptor of lymphocytes from normal subjects and patients with phaeochromocytoma: Studies in vivo. British Journal of Clinical Pharmacology, 5, 191-197.

Halaris, A. (2009). Comorbidity between depression and cardiovascular disease. International Angiology, 28, 92-99.

Halaris, A. (2013). Inflammation, heart disease, and depression. Current Psychiatry Reports, 15, 400.

Hamilton, M. (1960). A rating scale for depression. Journal of Neurology, Neurosurgery and Psychiatry, 23, 56-62.

Hare, D. L., Toukhsati, S. R., Johansson, P., \& Jaarsma, T. (2014). Depression and cardiovascular disease: A clinical review. European Heart Journal, 35, 1365-1372.

Heuser, I., Bissette, G., Dettling, M., Schweiger, U., Gotthardt, U., Schmider, J., et al. (1998). Cerebrospinal fluid concentrations of corticotropin-releasing hormone, vasopressin, and somatostatin in depressed patients and healthy controls: Response to amitriptyline treatment. Depression and Anxiety, 8, 71-79.

Hoeks, J., van Baak, M. A., Hesselink, M. K., Hul, G. B., Vidal, H., Saris, W. H., et al (2003). Effect of beta1- and beta2-adrenergic stimulation on energy expenditure, substrate oxidation, and UCP3 expression in humans. American Journal of Physiology Endocrinology and Metabolism, 285, E775-782.

Irwin, M. (2002). Psychoneuroimmunology of depression: Clinical implications. Brain, Behavior, and Immunity, 16, 1-16.

Izzo, J. L., Jr, Smith, R. J., Larrabee, P. S., \& Kallay, M. C. (1987). Plasma norepinephrine and age as determinants of systemic hemodynamics in men with established essential hypertension. Hypertension, 9, 415-419.

Jones, C. R., Hamilton, C. A., Whyte, K. F., Elliott, H. L., \& Reid, J. L. (1985). Acute and chronic regulation of alpha 2 -adrenoceptor number and function in man. Clinical Science, 68(Suppl 10), 129s-132s.

Kelly, C. B., \& Cooper, S. J. (1998). Plasma norepinephrine response to a cold pressor test in subtypes of depressive illness. Psychiatric Research, 81, 39-50.

Krause, M., Reinhardt, D., \& Kruse, K. (1988). Phaeochromocytoma without symptoms: Desensitization of the alpha- and beta-adrenoceptors. European Journal of Pediatrics, 147, 121-122.

Krogh, J., Videbech, P., Thomsen, C., Gluud, C., \& Nordentoft, M. (2012). DEMO-II trial. Aerobic exercise versus stretching exercise in patients with major depression-a randomised clinical trial. PloS One, 7, e48316.

Kuehl, L. K., Penninx, B. W. J. H., \& Otte, C. (2012). Depression: Risikofaktor für kardiovaskuläre Erkrankungen. Der Nervenarzt, 83, 1379-1384.

Lambert, E., Straznicky, N., Sari, C. I., Eikelis, N., Hering, D., Head, G., et al. (2013). Dyslipidemia is associated with sympathetic nervous activation and impaired en dothelial function in young females. American Journal of Hypertension, 26, 250-256.

Landsberg, L. (1996). Insulin and the sympathetic nervous system in the pathophysiology of hypertension. Blood Pressure, 1, 25-29.

Mancia, G., Bousquet, P., Elghozi, J. L., Esler, M., Grassi, G., Julius, S., et al. (2007). The sympathetic nervous system and the metabolic syndrome. Journal of Hypertension, 25, 909-920.

Mathers, C. D., \& Loncar, D. (2006). Projections of global mortality and burden of disease from 2002 to 2030. PLoS Medicine, 3, e442.

Morley, J. E., Thomas, D. R., \& Wilson, M. M. (2006). Cachexia: Pathophysiology and clinical relevance. The American Journal of Clinical Nutrition, 83, 735-743.

Mottillo, S., Filion, K. B., Genest, J., Joseph, L., Pilote, L., Poirier, P., et al. (2010). The metabolic syndrome and cardiovascular risk a systematic review and meta-analysis. Journal of the American College of Cardiology, 56, 1113-1132.

Mraz, M., Lacinova, Z., Drapalova, J., Haluzikova, D., Horinek, A., Matoulek, M., et al. (2011). The effect of very-low-calorie diet on mRNA expression of inflammationrelated genes in subcutaneous adipose tissue and peripheral monocytes of obese patients with type 2 diabetes mellitus. The Journal of Clinical Endocrinology and Metabolism, 96, E606-613.

Musselman, D. L., Tomer, A., Manatunga, A. K., Knight, B. T., Porter, M. R., Kasey, S., et al. (1996). Exaggerated platelet reactivity in major depression. The American Journal of Psychiatry, 153, 1313-1317.

Nakajima, Y., Yamada, M., Akuzawa, M., Ishii, S., Masamura, Y., Satoh, T., et al. (2013). Subclinical hypothyroidism and indices for metabolic syndrome in Japanese women: One-year follow-up study. The Journal of Clinical Endocrinology and Metabolism, 98, $3280-3287$.

O’Donnell, L., Owens, D., McGee, C., Devery, R., Hession, P., Collins, P., et al. (1988). Effects of catecholamines on serum lipoproteins of normally fed and cholesterol-fed rabbits. Metabolism, 37, 910-915.
Okamura, T., Nakajima, Y., Satoh, T., Hashimoto, K., Sapkota, S., Yamada, E., et al. (2015). Changes in visceral and subcutaneous fat mass in patients with pheochromocytoma. Metabolism, 64, 706-712.

Pariante, C. M., \& Lightman, S. L. (2008). The HPA axis in major depression: Classical theories and new developments. Trends in Neurosciences, 31, 464-468.

Penesova, A., Radikova, Z., Cizmarova, E., Kvetnansky, R., Blazicek, P., Vlcek, M., et al. (2008). The role of norepinephrine and insulin resistance in an early stage of hypertension. Annals of the New York Academy of Sciences, 1148, 490-494.

Petrak, O., Haluzikova, D., Kavalkova, P., Strauch, B., Rosa, J., Holaj, R., et al. (2013). Changes in energy metabolism in pheochromocytoma. The Journal of Clinical Endocrinology and Metabolism, 98, 1651-1658.

Petrak, O., Strauch, B., Zelinka, T., Rosa, J., Holaj, R., Vrankova, A., et al. (2010). Factors influencing arterial stiffness in pheochromocytoma and effect of adrenalectomy. Hypertension Research, 33, 454-459.

Sanders, V. M. (2012). The beta2-adrenergic receptor on T and B lymphocytes: Do we understand it yet? Brain, Behavior, and Immunity, 26, 195-200.

Schols, A. M., Buurman, W. A., Staal van den Brekel, A. J., Dentener, M. A., \& Wouters, E. F. (1996). Evidence for a relation between metabolic derangements and increased levels of inflammatory mediators in a subgroup of patients with chronic obstructive pulmonary disease. Thorax, 51, 819-824.

Services, U. S. D. H. H. (2010). How tobacco smoke causes disease: The biology and behavioral basis for smoking-attributable disease: A report of the surgeon general, Atlanta (GA).

Sherwood, A., Hinderliter, A. L., Watkins, L. L., Waugh, R. A., \& Blumenthal, J. A. (2005) Impaired endothelial function in coronary heart disease patients with depressive symptomatology. Journal of the American College of Cardiology, 46, 656-659.

Spasojevic, N., Gavrilovic, L., Kovacevic, I., \& Dronjak, S. (2009). Effects of antidepressants maprotiline and fluxilan on sympatho-adrenomedullary system in stressed rats. Autonomic Neuroscience, 145, 104-107.

Steptoe, A., \& Kivimaki, M. (2012). Stress and cardiovascular disease. Nature Reviews Cardiology, 9, 360-370

Stern, M. P., Williams, K., Gonzalez-Villalpando, C., Hunt, K. J., \& Haffner, S. M. (2004). Does the metabolic syndrome improve identification of individuals at risk of type 2 diabetes and/or cardiovascular disease? Diabetes Care, 27, 2676-2681.

Thornton, L. M., \& Andersen, B. L. (2006). Psychoneuroimmunology examined: The role of subjective stress. Cellscience, 2, 66-91.

Tisdale, M. J. (2009). Mechanisms of cancer cachexia. Physiological Reviews, 89, 381-410.

Troisi, R. J., Weiss, S. T., Parker, D. R., Sparrow, D., Young, J. B., \& Landsberg, L. (1991) Relation of obesity and diet to sympathetic nervous system activity. Hypertension, 17, 669-677.

Tsujimoto, G., Honda, K., Hoffman, B. B., \& Hashimoto, K. (1987). Desensitization of postjunctional alpha 1- and alpha 2-adrenergic receptor-mediated vasopressor responses in rat harboring pheochromocytoma. Circulation Research, 61, 86-98.

Veith, R. C., Lewis, N., Linares, O. A., Barnes, R. F., Raskind, M. A., Villacres, E. C., et al. (1994). Sympathetic nervous system activity in major depression. Basal and desipramine-induced alterations in plasma norepinephrine kinetics. Archives of General Psychiatry, 51, 411-422.

Ward, K. D., Sparrow, D., Landsberg, L., Young, J. B., Vokonas, P. S., \& Weiss, S. T. (1994). The relationship of epinephrine excretion to serum lipid levels: The Normative Aging Study. Metabolism, 43, 509-513.

Whooley, M. A., de Jonge, P., Vittinghoff, E., Otte, C., Moos, R., Carney, R. M., et al. (2008). Depressive symptoms, health behaviors, and risk of cardiovascular events in patients with coronary heart disease. Journal of the American Medical Association, 300, 2379-2388.

Yajima, H., Komatsu, M., Sato, Y., Yamada, S., Yamauchi, K., Sharp, G. W., et al. (2001). Norepinephrine inhibits glucose-stimulated, $\mathrm{Ca} 2+$-independent insulin release independently from its action on adenylyl cyclase. Endocrine Journal, 48, 647-654.

Young, J. B., \& Macdonald, I. A. (1992). Sympathoadrenal activity in human obesity: Heterogeneity of findings since 1980. International Journal of Obesity and Related Metabolic Disorders : Journal of the International Association for the Study of Obesity, 16, 959-967.

Zahn, D., Petrak, F., Uhl, I., Juckel, G., Neubauer, H., Hagele, A. K., et al. (2013). New pathways of increased cardiovascular risk in depression: A pilot study on the association of high-sensitivity C-reactive protein with pro-atherosclerotic markers in patients with depression. Journal of Affective Disorders, 146, 420-425.

Zelinka, T., Petrak, O., Strauch, B., Holaj, R., Kvasnicka, J., Mazoch, J., et al. (2007). Elevated inflammation markers in pheochromocytoma compared to other forms of hypertension. Neuroimmunomodulation, 14, 57-64.

Zuber, S. M., Kantorovich, V., \& Pacak, K. (2011a). Hypertension in pheochromocytoma: Characteristics and treatment. Endocrinology and Metabolism Clinics of North America, 40, 295-311 vii.

Zuber, S. M., Kantorovich, V., \& Pacak, K. (2011b). Hypertension in pheochromocytoma: Characteristics and treatment. Endocrinology and Metabolism Clinics of North America, 40, 295-311 vii. 